\title{
The Optimal Design and Realization of Survey Vessel Communication Power Supply System
}

\author{
Hongyuan Liu a , Anguo $\mathrm{Wu}^{\mathrm{b}}$ \\ China Satellite Maritime Tracking and Control Department, Jiangyin 214431, China. \\ aSDLHY123@163.com, b359988175@qq.com
}

Keywords: Communication power supply, UPS, Constant power discharge.

\begin{abstract}
This paper briefly analyzes the status quo of uninterruptible power supply of the survey vessel communication system, expounds the composition of communication power supply, principles and functions of uninterruptible power supply, and puts forward the optimal design scheme of the existing power supply system. This paper concentrates on the configuration of UPS and accumulator. In this paper, the accumulator capacity value is calculated according to the formula of battery constant power discharge. The power and number of UPS modules are configured according to the actual load capacity, and in the meantime, the UPS modules form redundancy. And then, the system is improved and implemented according to the optimal design scheme which could improve the unremittance, stability and reliability of the power supply of the system.
\end{abstract}

\section{Introduction}

Current uninterruptible power supply of the survey vessel communication system is provided by different types of UPS equipment. Because of the large number of communication equipment subsystems, and different UPS models and battery capacities, uninterruptible power supply capabilities are uneven in case of power outage, which is not conducive to the overall stability of communication system. In addition, UPSs in every subsystems are not centralized, and maintenance work is time-consuming and labor-intensive, and could not be done in a centralized method, which are not conducive to the improvement of the efficiency of equipment maintenance and management. Therefore, improving the existing independent and uninterruptible power supply mode and designing a relatively centralized and uninterruptible power supply system are of great practical significance to the improvement of the uninterruptible power supply capability and quality of the communication power system and to the enhancement of the overall stability of the communication system. At the same time, the design idea and system can also be applied to the measurement and control system so as to improve the reliability of the power supply of its equipment, and provide more reliable safeguard for the implementation of testing missions, and they are also of great promotion and application value.

\section{Application Status Analysis}

The status quo of uninterruptible power supply of the survey vessel communication system is featured as follows:

(1) Some equipment is not installed with UPS. For example, important equipment such as service bearer network subsystem, access switch, aggregation switch, firewall and security machine are not configured with UPS. In case of interruption of vessel power, the equipment will stop working, which will affect data transmission of testing missions and cause great impact on the missions.

(2) Part of the power supply equipment of the system is complex and of obsolete model. For example, for the high-frequency power switch equipment of the dispatching subsystem, its operation, maintenance and exception handling are extremely complex, and it is difficult to maintain and replace accumulator, which are not conducive to the stability of subsystems and emergency disposal. 
(3) The UPS of some subsystems have small capacities, which cannot meet the needs of uninterruptible power supply. For example, UPS accumulators of the unified time subsystem are of small capacities, and their power supply time is short.

(4) The UPS models of different subsystems are not unified, along with scattered equipment, enormous maintenance workload and low efficiency, so the centralized and unified management cannot be performed.

The above status quo has a great influence on the overall stability of the communication system equipment which seriously hinders the improvement of equipment maintenance and management capability.

\section{Optimal Design of Communication Power System}

In consideration of the characteristics of communication system, improving the existing power supply mode and designing centralized and unified communication power supply system can improve uninterruptible power supply capability, and achieve centralized control of equipment power supply, thereby enhancing system stability and equipment maintenance and management capability.

\subsection{Optimization Principle and Design.}

\subsubsection{Overall Design Requirements.}

According to the requirements of communication stabilized voltage supply, UPS equipment shall be installed in the communication system node facility room to ensure the power supply of all equipment in the communication facility room. In the event of power outage, under the protection of the UPS, the equipment in the facility room can work normally for at least 10 minutes.

\subsubsection{Principles and Main Functions.}

Under normal power supply, UPS provides pure and stable power supply to the load after rectifying and contravariant/inverter double conversing vessel power, while in the meantime it charges the storage battery via charging circuit. The storage battery is connected in parallel with DC bus. When power failure occurs, the storage battery can continuously output DC power supply to the inverter and supply power to the load, of which the switching time is zero. When the power supply is restored, vessel power will continue to provide power, while charging the storage battery.

In the case of UPS failure, the internal static switch automatically outputs the power by-pass of the ship, and the switching time is less than $4 \mathrm{~ms}$, so as to ensure emergency use. Set up maintenance bypass switch for UPS maintenance or emergency use.

After the UPS transformation, the power supply is sent back to the distribution subsystem. According to the different circuits and requirements, the power distribution subsystem will feed the power to the cabinet, the console and the electrical equipment. Each output circuit load switch adopts a small circuit breaker. When the line current exceeds the set current, the switch automatically trips, which has the protection function of short circuit and overload. The load switch is divided into group control to make the control mode more reasonable and flexible.

\subsection{System Optimization Design.}

To improve the power supply quality of communication system equipment, it is necessary to use UPS to provide high-quality power so as to ensure that the requirements of communication equipment are met. At the same time, to improve the stability of the equipment, it is of great necessity to use accumulators which are of large-capacities and can maintain necessary storage capacities. Therefore, the communication power system consists of three parts which are UPS subsystem, accumulator and power distribution subsystem.

\subsubsection{UPS Subsystem.}

UPS subsystem is the core equipment of communication power, which is responsible for supplying three-phase four-wire $220 \mathrm{~V} / 380 \mathrm{~V}$ power to the equipment for its use by isolating and transforming, and AC-DC conversing and filtering the input vessel power. A number of power modules form UPS array, and the power modules have dual conversion function, including rectifier, inverter, charging and control, etc. in order to eliminate the bottleneck of reliability. 
According to the actual load capacity requirements, select the appropriate module power and quantity, and make up the redundancy of $\mathrm{N}+1$ or $\mathrm{N}+2$. The $\mathrm{N}$ module can meet the requirements of the system capacity, when a fault occurs in power module, the operation can automatically exit the array, pull it out to replace or repair, other normal module can fully guarantee the system capacity requirements, does not affect the normal power supply, to ensure the reliability of the system.

\subsubsection{Battery.}

The role of accumulator is to store electrical energy. When power supply is interrupted, electrical energy is released and AC power is output via inverter to maintain the normal power supply of UPS for a certain period of time. Backup time is in direct proportional to accumulator capacity and inversely proportional to the size of load.

\subsubsection{Distribution System.}

The distribution system outputs three phase four wire power supply to the cabinet and the console. When a phase power supply is abnormal, it will not affect the work of other two phases to meet the requirements of two sets of power supply.

The output switches of the distribution cabinets use small circuit breakers. The setting current is determined according to the current size of the loop, which ensures the full load of the circuit and the overload protection function.

\section{The Realization of the Design}

There are 5 facility rooms for communication system, so 5 sets of UPS power systems need to be installed. The power supply and distribution system of every facility room is composed of UPS cabinets, power distribution cabinets, battery house, power distribution cables, etc. and the composition diagram of the power supply and distribution system is shown in Figure 1.

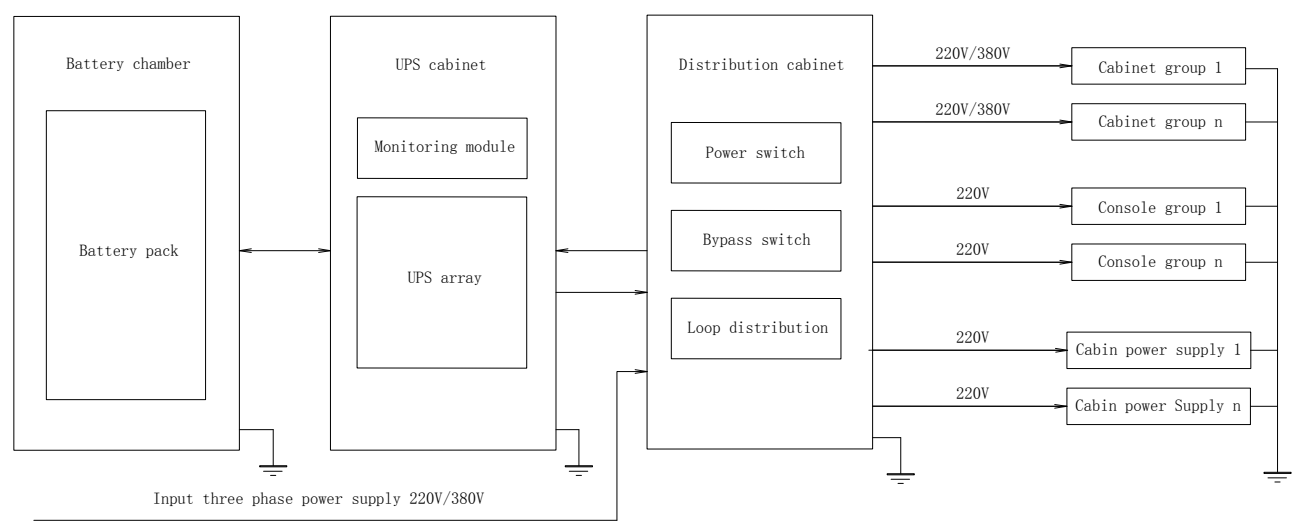

Figure 1 system composition block diagram

\subsection{Power Supply Capacity Analysis.}

The actual average workload is designed as $1.5 \mathrm{kVA}$ and $0.5 \mathrm{kVA}$ respectively for every equipment cabinet and workbench. According to the number of equipment, the demand for power supply capacity of the machine room is shown in Table 1.

Table 1 demand table for power supply capacity of machine room

\begin{tabular}{|c|c|c|c|c|c|c|}
\hline Serial Number & Computer Room & Cabinet & $\begin{array}{l}\text { Work bench } \\
\text { Individual }\end{array}$ & $\begin{array}{c}\text { Cabinet Capacity } \\
(\mathrm{kVA})\end{array}$ & $\begin{array}{c}\text { Work bench Capacity } \\
\qquad(\mathrm{kVA})\end{array}$ & $\begin{array}{l}\text { Total } \\
(\mathrm{kVA})\end{array}$ \\
\hline 1 & 1\#Computer room & 9 & 8 & 13.5 & 4 & 17.5 \\
\hline 2 & 2\#Computer room & 6 & 8 & 9.0 & 4 & 13.0 \\
\hline 3 & 3\#Computer room & 21 & 12 & 31.5 & 6 & 37.5 \\
\hline 4 & 4\#Computer room & 13 & 0 & 19.5 & 0 & 19.5 \\
\hline 5 & 5\#Computer room & 7 & 4 & 10.5 & 2 & 12.5 \\
\hline
\end{tabular}

It can be seen from the table that the maximum and minimum capacity is $39.1 \mathrm{kVA}$ and $14.1 \mathrm{kVA}$, respectively. Considering all factors, the design of $3 \#$ and $4 \#$ machine room is $60 \mathrm{kVA}$, and each 
group of power modules is $20 \mathrm{kVA}$ UPS, which can form $2+1$ redundant configuration. The 1\#, 2\#, $5 \#$ machine room is designed to be $40 \mathrm{kVA}$, which can form $1+1$ redundancy. Diagram of the power supply system of the machine room as shown in Figure 2.

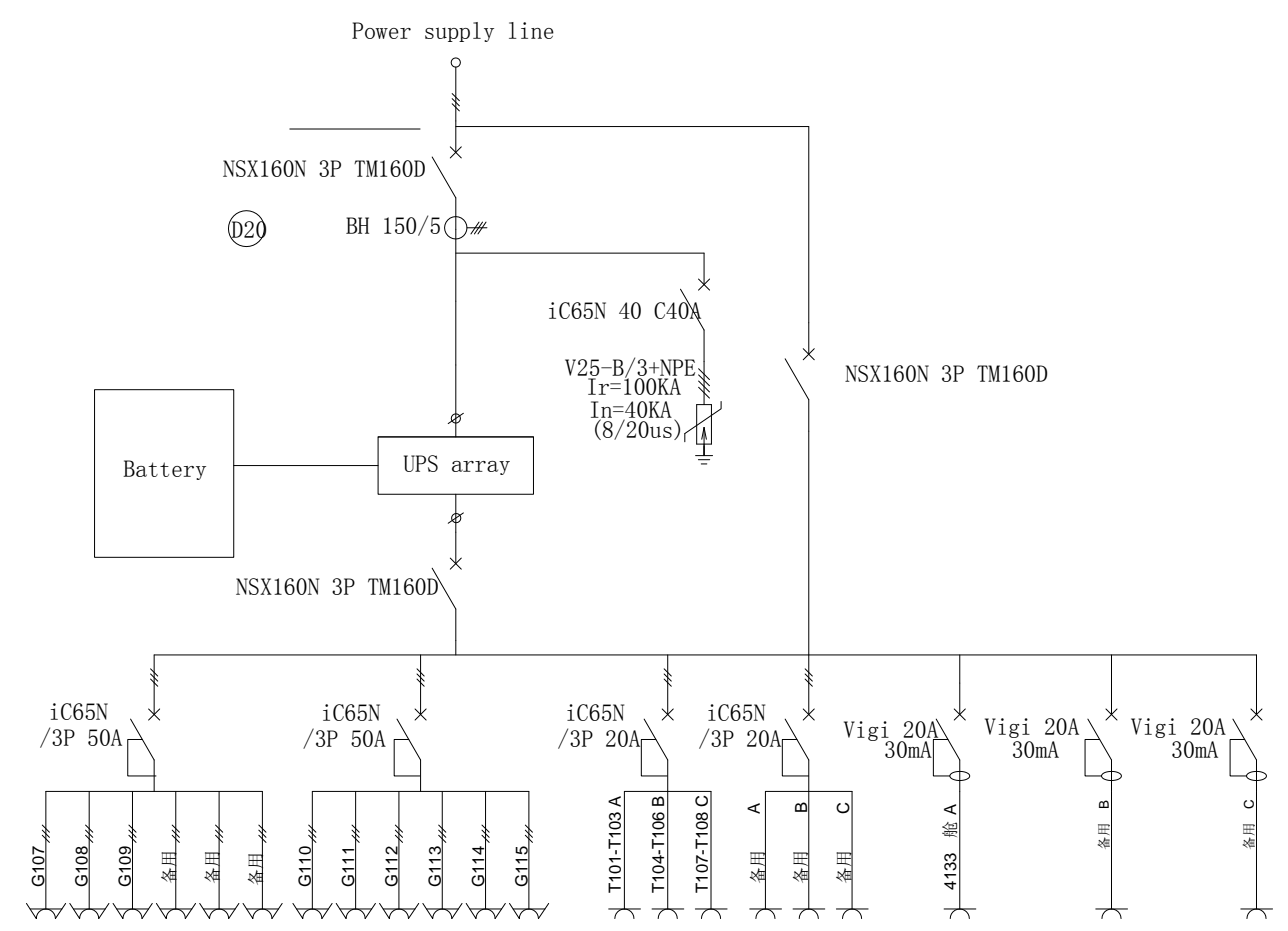

Figure 2 Schematic diagram of electrical system in machine room

\subsection{Accumulator Configuration Design.}

Because battery discharge time is relevant to discharge current, ambient temperature, load type, discharge rate, battery capacity and other factors, the required battery capacity value is calculated according to "Battery Constant Power Discharge Data Sheet". The formula is as follows:

$$
W=(P \times \cos \varphi) \div(\pi \times N \times 6)
$$

$\mathrm{P}-$ - Nominal output power of UPS power supply

$\cos \varphi$ — Power factor of load 0.9

$\pi$ - Efficiency of UPS inverter 0.95

$\mathrm{N}$ - - Battery number

Battery capacity calculation when the actual working load is $40 \mathrm{kVA}$

$$
\mathrm{W}=(40000 \times 0.9) /(0.95 \times 20 \times 6)=316 \mathrm{~W}
$$

According to the battery $12 \mathrm{~V} 100 \mathrm{Ah}$ constant power discharge meter 2 , it is known that under the $1.75 \mathrm{~V}$ cut-off voltage, the constant power discharge power is $337.7 \mathrm{~W}$ for 10 minutes, so 20 $12 \mathrm{~V} 100 \mathrm{Ah}$ batteries can meet the discharge requirements.

Table 2 12V100Ah battery constant power discharge data table

\begin{tabular}{cccccccc}
\hline One Node Battery Cut-off Voltage & $5 \mathrm{~min}$ & $10 \mathrm{~min}$ & $15 \mathrm{~min}$ & $20 \mathrm{~min}$ & $30 \mathrm{~min}$ & $45 \mathrm{~min}$ & $60 \mathrm{~min}$ \\
\hline $1.75 \mathrm{~V}$ & 437.8 & 337.7 & 292.2 & 213.6 & 184.8 & 129.1 & 107.2 \\
\hline
\end{tabular}

Battery capacity calculation when the actual workload is $20 \mathrm{kVA}$ load

$$
\mathrm{W}=(20000 \times 0.9) /(0.95 \times 20 \times 6)=158 \mathrm{~W}
$$

According to the battery $12 \mathrm{~V} 65 \mathrm{Ah}$ constant power discharge meter 3 , it is known that under the $1.75 \mathrm{~V}$ cut-off voltage, the constant power discharge power of 10 minutes is $247 \mathrm{~W}$, so the 20 $12 \mathrm{~V} 65 \mathrm{Ah}$ battery can meet the discharge requirements.

Table 3 12V65Ah battery constant power discharge data table

\begin{tabular}{cccccccc}
\hline One Node Battery Cut-off Voltage & $5 \mathrm{~min}$ & $10 \mathrm{~min}$ & $15 \mathrm{~min}$ & $20 \mathrm{~min}$ & $30 \mathrm{~min}$ & $45 \mathrm{~min}$ & $60 \mathrm{~min}$ \\
\hline $1.75 \mathrm{~V}$ & 321 & 247 & 220 & 165.1 & 131.8 & 96.48 & 79.82 \\
\hline
\end{tabular}


According to the technical requirements, 60kVA UPS configuring 12V100Ah battery 20 sections, 40kVA UPS configuring 12V65Ah battery 20 knots, which can meet the requirement of full load power supply longer than 10 minutes.

\subsection{The Realization of Optimal Design.}

The total installation UPS capacity of 3 \# and 4 \# facility room is 60kVA UPS of which the output power factor is 0.8 , and the maximum load capacity is $48 \mathrm{~kW}$. For other facility rooms, the total installation capacity is 40kVA UPS of which the output power factor is 0.8 , and the maximum load capacity is $32 \mathrm{~kW}$.

\subsubsection{Distribution System.}

The power distribution cabinets and UPS cabinets are installed in facility room. The operation surface is in the front of power distribution cabinets, which is divided into three parts--the indicator area, the main switch area and shunt control area, can display the voltage, current, power and other parameters of the power supply, and has functions of power input and output, and bypass and shunt control.

\subsubsection{UPS Subsystem.}

The UPS employs Legrand modular UPS. And every power module is single-phase 6.7kVA, and every three modules constitute a set of three-phase power supply (20kVA). Multiple modules can be run in parallel, and any single module damage does not affect normal operation.

The UPS model is TRIMOD60, and 3 \# and 4 \# room (60kVA UPS) in the communication are configured with $2+1$ redundancy, each with nine pieces. Other machine rooms (40kVA UPS) are configured with $1+1$ redundancy, each with six pieces.

\subsubsection{Battery.}

The battery cabinets are installed in the power supply house. The battery cabinets of the 4 \# and 5 \# facility rooms are in 1\# power supply house, the battery cabinet of 3 \# facility room is in 2 \# power supply house, and the power cabinets of 1\# and 2\# facility rooms are in 3\# power supply house.

According to the two kinds of capacity of UPS, the 20 section of the $12 \mathrm{~V} / 65 \mathrm{Ah}$ battery is installed in the battery cabinet of the 40kVA UPS. The battery cabinet of 60kVA UPS is installed in the 20 section of the 12V/100Ah battery.

\subsubsection{Equipment Grounding.}

The cabinet room set up two small grounding bus are respectively positioned on both sides of the rear of the cabinet, the cabinet and a set of equipment on the right side of the shell is connected securely to the cabinet end cited below, as safety, security and the cabinet below the bus. On the left side of a group and the equipment is working, and lead to a cabinet work end, as work, and the following work connected to the busbar cabinet. Safe bus and bus work were installed in the cabinet below, and reliable connection with the hull.

\section{Conclusion}

Through the calculation and design of UPS and accumulator configuration requirements, the communication power system is improved and realized. Through the actual use, the feasibility of the system optimization scheme has been tested, and the purpose of improving system power supply stability, stability and reliability has been achieved. This design can also be widely applied to the measurement and control system of survey vessels, so as to provide a more reliable guarantee for better execution of testing missions.

\section{References}

[1]. Zhang Liguo, Jiang Jingyi. Series Connected Battery Unitvoltage Inspects the Meter. Modern Power Electronics Technology. Vol.20 (2006).

[2]. Lv Yongjun. Design of Intelligent On-line Monitor of Battery. Foreign Electronic Components.No.9, September 2001. 
[3]. Li Shujing, Lin Ling, Li Gang.Research on Method of Measuring Voltage in a Serial Battery Cluster.The Journal of Instrument and Instrument.August.2003,Vol. 24 (4).

[4]. John Chatzakis,Kostas Kalaitzakis,Designing a New Generalized Battery Management System,IEEE Transaction on Industural Electronics,VOL.50,NO.5,2003.9.

[5]. Pritpal Singh, Craig Fennie, Jr, et al.Fuzzy Logic Modelling of State-of-charge and Available Capacity of Nickel metal Hydride Batteries[C].Journal of Power Sources.2004, 136.

[6]. Boris Tsent.Battery Managent for Hybrid Electric Vehiele and Teleconununieation Application.2002 IEEE.

[7]. Liu Junfeng. Single voltage detection system in charge and discharge process of battery. Modern urban rail transit ([J].2005) fifth phase P:41-42

[8]. Wang Fushun, Zhang Shuguang, Shao Limin, et al.The single cell voltage automatic circuit detection system of battery group [J]. agricultural research.2006.02

[9]. Chins Moo,Yao C.Hsieh,et al.Charge equalization for series-connected batteries. IEEE Transactions on aerospace and electronic systems.2003,Vol.39, Vol.39 (No. 2):pp:704-710

[10]. C.S.Moo,Y.C.Hsieh,I.S.Tsai,et al.Dynamic charge equalisation for series-connected batteries. IEEE ICIT'02. 2002, p: 444-459. 